\title{
BREVE RECUENTO HISTÓRICO DE LAS PRÁCTICAS FILOSÓFICAS
}

\section{BRIEF HISTORICAL RECORD OF PHILOSOPHICAL PRACTICES}

\author{
Lic. Mario Fernando de Jesús Campos Trejo \\ UNIVERSIDAD AUTÓNOMA DE CHIAPAS \\ mfjct94@gmail.com \\ Licenciado en Filosofía y estudiante de la \\ Especialidad en Procesos Culturales Lecto- \\ Escritores (UNACH)
}

\section{Resumen}

Volpone citado en el giro práctico de la filosofía de Gabriel Arnaiz (2007), menciona que un problema fundamental es el hecho que las Prácticas filosóficas nacieron de manera independiente unas de otras, en distintos momentos históricos, contextuales, culturales y sociales, con objetivos diferentes entre sí. Esto ha conllevado a una problemática al momento de situar el nacimiento de las Prácticas Filosóficas de manera general puesto que al hacer un recuento histórico se presentan fechas diferentes, autores distintos, formas de pensamiento con objetivos que difieren entre sí. No es hasta finales de los años 90 aproximadamente en que estas prácticas comienzan a observarse rasgos en común, y se empiezan a mirar unas con otras.

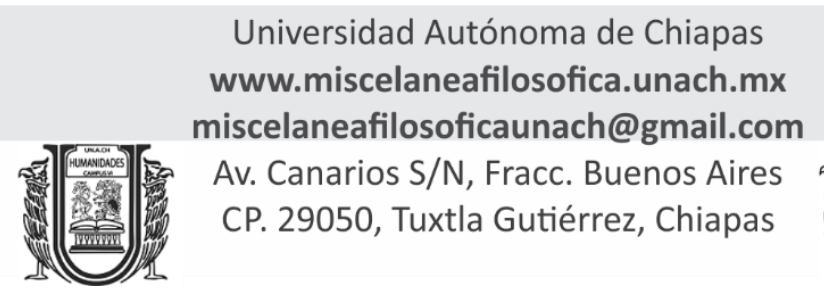


| Cuatrimestral Facultad de Humanidades Campus VI Reserva de Derechos al Uso Exclusivo No.: 04-2018-060814012200-203| ISSN: 2594-1755

Año II | Número 6 | Mayo- Agosto 2019

\title{
ARTÍCULOS
}

Palabras clave: Prácticas Filosóficas, Filosofía para Niños, Filosofía Aplicada

\begin{abstract}
Abstrac
Volpone cited in the practical turn of the philosophy of Gabriel Arnaiz (2007), mentions that a fundamental problem is the fact that the philosophical practices were born independently from each other, at different historical, contextual, cultural and social moments, with different objectives each. This has led to a problem at the time of placing the birth of the Philosophical Practices in a general way since in doing a historical recount different dates are presented, different authors, forms of thought with objectives that differ among themselves. It is not until the end of the 1990s that these practices begin to be observed in common, and begin to look at each other.
\end{abstract}

Key words: Philosophical Practices, Philosophy for Children, Applied Philosophy

A partir de la época antigua podríamos remitir el nacimiento de una práctica de la filosofía desde Epicuro, por ejemplo. Pero el referente principal lo encontramos en Sócrates quien fue un antiguo filósofo griego del siglo $\mathrm{V}$ a. C. el trabajo de nuestro filósofo consistía en parir ideas mediante el método sobre el cual versan la mayor parte de las Prácticas Filosóficas, la mayéutica.

Así, el padre de la filosofía, se considera el mayor referente de las Prácticas filosóficas, pues con él se asienta el método filosófico que permite dar paso al 
| Cuatrimestral Facultad de Humanidades Campus VI Reserva de Derechos al Uso Exclusivo No.: 04-2018-060814012200-203| ISSN: 2594-1755 Año II | Número 6 | Mayo- Agosto 2019

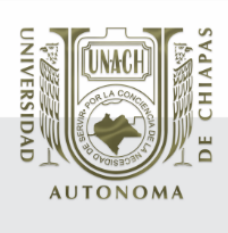

\section{ARTÍCULOS}

que atañe a la salud del alma" (Epicuro, 1999, pág. 405) La filosofía, así, toma un papel fundamental en el hombre, pues esta disciplina tiene características propias que le distinguen para el desarrollo del pensamiento, para él, la filosofía es una medicina para el alma del hombre, razón por la que es importante el desarrollo de un pensamiento de carácter filosófico en las personas, desde una edad temprana, pero esto no es justificante para no acercarse a la filosofía o a la reflexión filosófica si ya se es adulto, pues agregando un poco a la postura de Epicuro, podríamos atrevernos a decir, nunca es tarde para adentrarse a la labor reflexiva del pensar, nunca es tarde para acercarse a filosofar. Nunca es tarde para adentrarse en ella y nunca se es demasiado joven para iniciarse en ella.

Está claro que existieron otros filósofos de la antigüedad que dieron aportes a las bases de las Prácticas Filosóficas, al no mencionarse no significa que sean menos importantes pero dada la cantidad de información nos hemos centrado principalmente en estos dos filósofos (Sócrates y Epicuro) pues son las mayores referencias que presentan una estrecha relación con las Prácticas Filosóficas.

Para poder llegar a trazar una línea histórica de las Prácticas Filosóficas fue preciso recurrir a diferentes autores que se han adentrado a la ardua labor de ordenar cronológicamente estas Prácticas, pero cada quién lo realizó a partir de la práctica que realizan por lo que podemos ver que Marinoff va a centrar el nacimiento de las Prácticas Filosóficas a partir de la labor que el realiza en sus consultorías, Volpone desde la mirada de las Prácticas a las que se enfoca y Brenifier desde las Prácticas Filosóficas en las que se encuentra actualmente activo. Razón por la que nos dimos a la tarea de juntar los hechos más relevantes, de las investigaciones de estos autores y a partir de ello ordenarlos cronológicamente 
